\title{
Establishing a northern Eurasian paleoecological database
} \section{9-23 March 2007 \\ Heather Binney and Mary Edwards \\ University of Southampton, UK; \\ h.a.binney@soton.ac.uk}

Jesus College and Oxford University Centre for the Environment, UK,

\section{Background}

QUEST (Quantifying and Understanding the Earth System, 2004-2010) is the UK Natural Environment Research Council's Directed Program for Earth System Science. QUEST has 3 research themes, one of which addresses the question: 'How is atmospheric composition naturally regulated on time scales up to a million years?' Within this Theme, QUEST-Deglaciation uses climate models to simulate past climatic and atmospheric conditions since the Last Glacial Maximum (LGM) and evaluates the simulations using observational evidence of paleo-wetlands, paleo-fire, stable isotopes and vegetation reconstructions.

\section{Reconstruction of vegetation patterns since the LGM}

In QUEST-Deglaciation, maps of changing vegetation patterns from c. $21 \mathrm{kyr}$ to present are under construction, with the focus on sites north of $40^{\circ} \mathrm{N}$.

Since the start of the project in 2006, extensive progress has been made in enhancing existing pollen and plant macrofossil databases. The database includes records from previously data-sparse areas such as southeastern Europe; however, there is still a large gap, particularly in macrofossil data, in the Former Soviet Union (FSU), a critical region for the evaluation of the climate simulations.

At a meeting hosted by Professor Sandy Harrison in March 2005, it was established that good records were available from the FSU and that Russian researchers were willing to collaborate on the development of a database. It became clear that the most efficient way of doing this would be to engage the relevant community in a workshop where data could be entered directly to the database to ensure consistency and scientific accuracy, and where there would be opportunity for 'on-site' analyses and discussion of the combined dataset.

\section{Outcomes of the Workshop}

The workshop (which was partly funded by PAGES) included nineteen invited scientists, nine of whom are FSU nationals. Over a four-day period, the database was populated with data from 237 new sites with in-

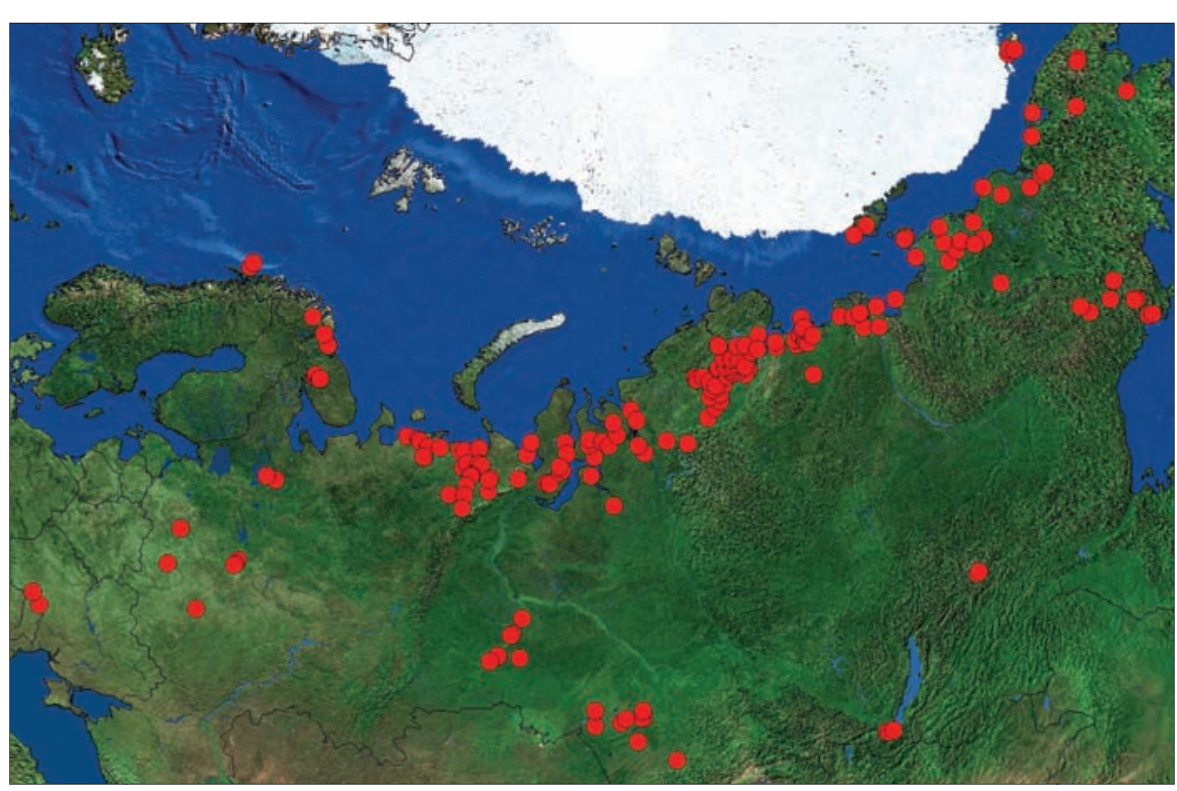

Figure 1. Location of sites entered in the database.

formation on 300 taxa in both quantitative and presence/absence form. The sites were radiocarbon dated and Maarten Blaauw (Queen's University, Belfast) undertook the calibration and age-depth modeling. The exercise was successful, and participants were keen both to continue to enter any additional data they had upon return to their home countries and to participate in further joint analyses of the data.

Figure 1 shows the sites entered into the database. Ages range from $58 \mathrm{kyr}$ to present (most were $<21 \mathrm{kyr}$ ). Additional meta-data such as landscape description, depositional context, local/regional vegetation and type of remains (e.g. leaf fragment, catkin bract) were also recorded.

\section{Results and future plans for use of the database}

Aside from the evaluation of the QUEST climate models, several other key research issues can be addressed including, for example, the pattern of postglacial expansion of trees and the treeline history in northern Eurasia. Initial assessment of the data shows early occupation of northern regions by trees in the Holocene. Figure 2 shows the location of macrofossils derived from trees (excluding Salix spp.) with ages greater than $10 \mathrm{cal}$ kyr BP.

Other biogeographic questions that can be addressed with the database include the presence, or otherwise, of trees outside postulated areas of European refugia, mi-

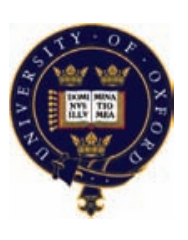

Quantifying and Understanding the Earth System

University of Southampton

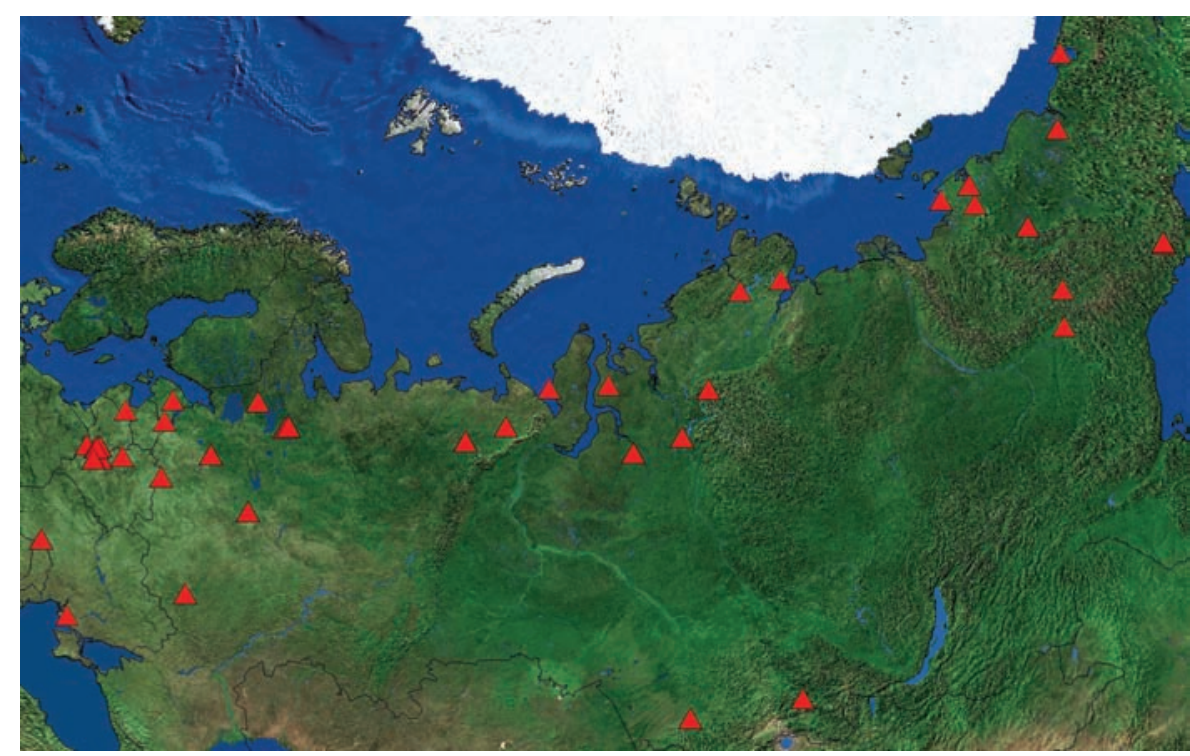

Figure 2: Macrofossils derived from trees (excluding Salix spp.) with ages $>10$ cal kyr BP. 
gration rates of trees across continents, the affects of landscape on the nature of fossil records, and the implications of observed distribution patterns for current and future patterns of species diversity and genetic diversity. The establishment of the database also contributes to the goals of the Pan-Arctic Initiative (PAIN II), an unfunded international initiative to map circum-arctic vegetation data from $21 \mathrm{kyr}$ to present, which contributes to the activities of the
Paleoclimate Modeling Intercomparison Project (PMIP II).

\section{Publications and public availability of the database}

The final version of the database will be made publicly availably via the QUEST web portal with links from the PAGES website and the European Pollen Database. It is envisaged that this will take place in early
2008 following publication of a multi-authored paper in the autumn of 2007.

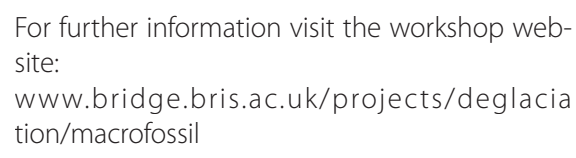

Other website links:

QUEST: quest.bris.ac.uk/

QUEST Deglaciation: www.bridge.bris.ac.uk/proj ects/deglaciation

\section{First Central African PAGES Workshop}

\section{University of Yaounde I, Cameroon, January 25-27, 2007}

\section{Richard Tanwi Ghogomu}

Department of Earth Sciences, University of Yaounde I, Cameroon; rghogomu@yahoo.com

Paleoclimate, Past to Recent Environmental Change and Human Interactions was the title of the First Central African PAGES Workshop held from the 25-27 January 2007 at the University of Yaounde I, Cameroon. This three-day gathering was designed to bring together paleoscientists, researchers, teachers, stakeholders, and decision/policy makers, with the goal of encouraging research collaboration and capacity building, and attempting to close the gap between policy and research in paleoscience and global change. The workshop attracted over 70 participants from the Central African subregion and beyond. Broadly defined, Central Africa embraces that part of the continent that straddles both sides of the equator for about $15^{\circ}$ and is drained largely by the Congo River system (Fig. 1). It has a wide range of ecosystems varying from mangroves at the coastlines through tropical rainforest at the equator to grassland savannah and Soudano-Sahelian types towards the north. Central Africa has a population of over 100 million with one of the highest annual population increases (2.4-3.5\%) in the world. Natural (landslides, volcanic eruption) and human-induced disasters (drought, desertification, flood, epidemics and refugees) are frequent and on the rise.

The first day focused on opening activities, lectures and keynote presentations.

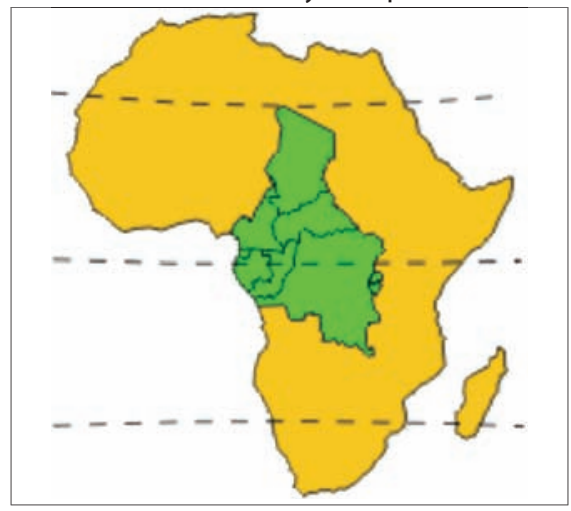

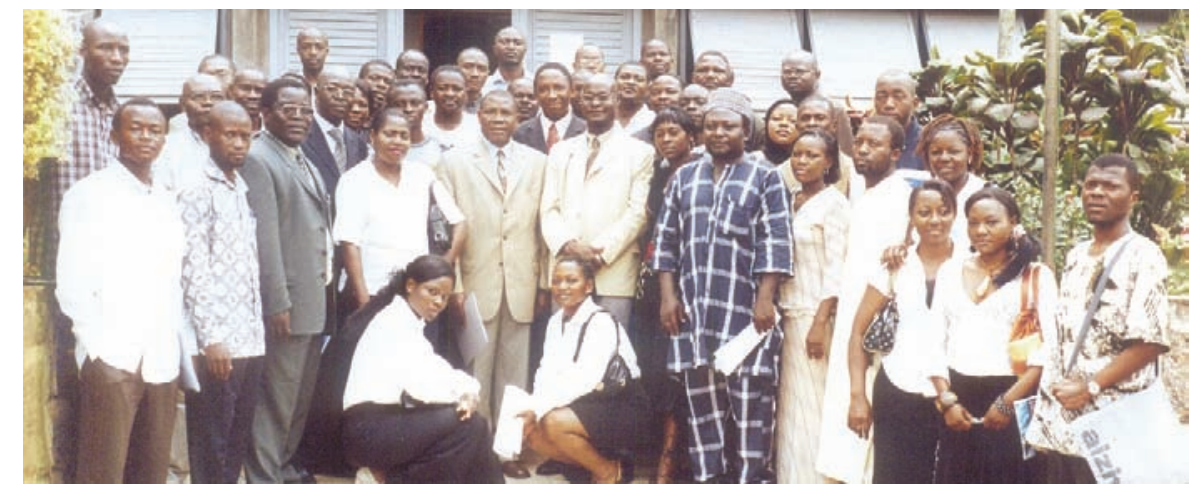

Figure 2: Participants of the first Central African PAGES Workshop.

This was followed by a session on instrumental climatic records. The second day was composed of a chain of presentations ranging from Holocene paleoclimates to recent ecosystems and human interactions, and concluding with past natural and human-induced disasters in the region. Some interesting findings presented on this day included a most remarkable drop in rainfall in the region, over the second half of the 20th centruy. Even Debuncha (at the foot of Mt Cameroon), which used to be the second wettest place in the world with over 12 $\mathrm{m} /$ year in the 1960's, has witnessed a drop to less than $10 \mathrm{~m} /$ year today. Research using proxy data from lake sediment cores, fossil dunes, river terraces and stalagmites was also presented. These were used to assess climate variability across a range of temporal scales (Holocene, Quaternary, and last millennium to present). Paleoclimatic reconstructions suggested a humid phase for the first half of the Holocene in Central Africa, while a dry phase was evident between 5-4 kyr BP for the Lake Chad and Adamawa regions. In the south of this region, the dry phase seems to come much later (2.8-1.3 kyr BP) after which a humid phase would have persisted till today. Multi-spectral remote-sensing data was also presented and showed that deforestation and fuel wood-gathering (in the savannah-Sahel), together with the expansion of agricultural land, were the major changes in land cover types.

On the third day, a panel discussion was held on the problems involved in paleoscience and global change research in Central Africa and the way forward. It was realized that while the required human resource is available and needs capacity building, the required physical infrastructure is limited. Participants also recommended that Central African scientists should collaborate with colleagues in the sub-region, rather than only with overseas counterparts, as has previously been the case.

The main outcomes of the workshop include:

1) The draft of a Central African PAGES website to enhance sharing of information and showcase central African paleoscience. The workshop proceedings, reports, extended abstracts and PowerPoint presentations will be available on this website.

2) A listserver to facilitate networking and collaboration among members of varied disciplines and geographic locations. To subscribe, please email rghogomu@yahoo.com.

The next Central African PAGES Workshop is to be held in Chad in 2009. 